\title{
Radioresistance and Cancer Stem Cells: Survival of the Fittest
}

\section{Lei Sun, Stephanie M Cabarcas and William L Farrar*}

Cancer Stem Cell Section, Laboratory of Cancer Prevention, Center for Cancer Research, National Cancer Institute at Frederick, 1050 Boyles Street, Building 560 , Room 21-81, Frederick, MD 21702, USA

\begin{abstract}
Cancer arises from the accumulation of genetic mutations and aberrant epigenetic modifications in normal cells. Cancer stem cells (CSCs) have been described as a unique tumorigenic population of cells within the tumor mass that have the ability to self-renew and differentiate. In the past few years, the existence and nature of CSCs has served as one of the most controversial topics in the field of cancer biology; however, more recently, there is an abundant amount of evidence that demonstrates their existence. CSCs are believed to be responsible for resistance against conventional therapies, such as radiotherapy that contributes to uncontrolled tumor growth, metastasis and subsequently, patient demise. In this review, we summarize the mechanism(s) by which CSCs are radioresistant, including their enhanced DNA damage response, cell cycle status and the role of the CSC niche. Moreover, by using the Oncomine database, we display data from our laboratory and other groups demonstrating that CSCs have an increased expression of radioresistance genes, which are also involved in carcinogenesis, metastasis and patient relapse. In addition, we provide data from prostatospheres derived from primary patient cells demonstrating that the RAN signaling pathway is one of the top upregulated pathways within the CSC population. Therefore, we hypothesize that the RAN signaling pathway is related to the radioresistance property of CSCs. We briefly review this burgeoning field of study on the biological behavior of CSCs and provide new suggestions for the development of future therapies to target radioresistant CSCs in both pharmaceutical investigations and clinical trials.
\end{abstract}

Keywords: Cancer stem cells (CSCs); Radiotherapy; Radioresistance; Carcinogenesis

\section{Introduction}

\section{The concept of cancer stem cells}

Cancer is defined as the uncontrolled growth of abnormal cells in the body and it is one of the leading causes of death worldwide. In 2010, over a half million cancer deaths are estimated to have occurred in the United States [1]. The individual cells inside a bulk tumor are considered to vary in their properties, which is termed heterogeneity. To date, there are two models explaining the models of cancer development: the stochastic model and the hierarchy model [2,3]. In the stochastic model, all the cells are biologically homogenous within the tumor and their characteristics are regulated by both intrinsic and extrinsic factors which influence the heterogeneity of the cancer cells. On the contrary, the hierarchy model predicts that a tumor consists of heterogeneous cells and there is a specific population of the cells within the tumor that have tumorigenic ability. The identification of this unique population, termed cancer stem cells (CSCs), within the heterogeneous population in the bulk tumor has established much interest in the biological and molecular characterization of this recently acknowledged subpopulation.

CSCs were first identified in human acute myeloid leukemia (AML) cells in 1994 [4]. Lapidot et al. fractionated AML cells based on cell surface marker expression and found that a $\mathrm{CD} 34^{+} \mathrm{CD} 38$ population were able to engraft severe combined immune-deficient (SCID) mice and develop progenitors of human leukemia, but the $\mathrm{CD} 34^{+} \mathrm{CD} 38^{+}$and $\mathrm{CD} 34^{-}$fractions were not [4]. CSCs were then identified in many solid tumors, including breast, prostate, pancreas, brain, colon, liver, lung, ovary and skin cancers [5-7]. There are several methods used to enrich for the CSC population in total cancer cells, including flow cytometry based on cell surface marker gene expression of CD44, CD24, CD133, and $\alpha 2 \beta 1[8,9]$. In addition, CSCs can be enriched for in cultures of serum free stem cell media in attachment independent systems, resulting in the development of 'spheres' [10-13].
In comparison to the total adherent population, spheres express higher levels of stem associated genes and have higher tumorigenic capacity in mice with similar levels to sorted CSCs. Additionally, recent work in our laboratory has shown that invasive prostate cancer cells are more tumorigenic, compared with their non-invasive counterparts [14]. Klarmann et al. demonstrated using invasion chambers and highly defined stem cell media that we can enrich for the population that express stem genes and have CSC-like properties in prostate cancer cell lines. These invasive cells have undergone epithelial to mesenchymal transitions (EMT) and are much more tumorigenic when injected into SCID mice [15]. Overall, CSCs not only have the ability to self-renew and give rise to differentiated cancer cells, but also form colonies in vitro and tumors in vivo with a small number of cells (100-1000 cells), compared with total cancer cells [16].

The continuous characterization of CSCs supports their existence and there is evidence suggesting that they may be responsible for both chemo- and radioresistance, leading to cancer cell survival, invasion, metastasis and further patient demise. In this review, we will summarize the evidence supporting the radioresistant characteristics of CSCs and propose how to make them more sensitive to radiotherapies, which can provide new insights for pharmaceutical investigations and clinical trials.

*Corresponding author: William L Farrar, Cancer Stem Cell Section, Laboratory of Cancer Prevention, Center for Cancer Research, National Cancer Institute at Frederick, 1050 Boyles Street, Building 560, Room 21-81, Frederick, MD 21702 , USA, E-mail: farrarw@mail.nih.gov

Received May 16, 2011; Accepted June 16, 2011; Published June 18, 2011

Citation: Sun L, Cabarcas SM, Farrar WL (2011) Radioresistance and Cancer Stem Cells: Survival of the Fittest. J Carcinogene Mutagene S1:004. doi:10.4172/2157 2518.S1-004

Copyright: (c) 2011 Sun L, et al. This is an open-access article distributed unde the terms of the Creative Commons Attribution License, which permits unrestricted use, distribution, and reproduction in any medium, provided the original author and source are credited. 
Citation: Sun L, Cabarcas SM, Farrar WL (2011) Radioresistance and Cancer Stem Cells: Survival of the Fittest. J Carcinogene Mutagene S1:004. doi:10.4172/2157-2518.S1-004

\section{Cancer stem cells and radioresistance}

It is hypothesized that cancer cells are heterogeneous in their radiation response and CSCs are most resistant to radiation [17]. To date, the degree of radiosensitivity is recognized to be related to both intrinsic properties, including DNA repair, cell cycle status, survival pathways and extrinsic properties which include cues from the extracellular environment. It is these combinatorial factors which are hypothesized to enable CSCs to withstand radiation insult. In order to develop approaches which can enhance the response of CSCs to radiotherapy, it is necessary to understand the features that contribute to $\mathrm{CSC}$ radiosensitivity.

DNA repair and cell cycle status: There is mounting evidence suggesting that to achieve increased genomic stability, CSCs utilize DNA repair mechanisms to maintain themselves in a stable state upon radiation. DNA repair mechanisms include double-strand break repair $[18,19]$, mismatch repair $[20,21]$, nucleotide excision repair [22] and base excision repair [22,23]. A number of proteins involved in the process of DNA repair include ATM, BRCA1/2, CHEK2, p53, and RAD family proteins $[18,24]$. These proteins are involved in the process of aberrant DNA recognition, cell cycle arrest and DNA repair [25-28]. Failure of this mechanism can result in genomic instability, accumulated mutagenesis and lead to carcinogenesis [29,30]. The dysfunction of these cancer susceptibility genes that normally function in DNA repair can increase the risk of both familial and sporadic breast cancers. A hallmark trait of DNA damage is $\gamma \mathrm{H} 2 \mathrm{AX}$ levels (the phosphorylated form of histone $\mathrm{H} 2 \mathrm{AX}$ ) and it is used for evaluating DNA repair dynamics [31-33]. In a study using MCF7 and MDAMB-231 breast cancer cells, radiation treatment enriched a relatively radioresistant side population with stem characteristics [34]. In this same study, $\mathrm{CD} 44^{+} \mathrm{CD} 24^{- \text {llow }} \mathrm{CSC}$ sere isolated and propagated as mammospheres and upon treatment with radiation between 2 Gy and $6 \mathrm{~Gy}$, increased levels of $\gamma \mathrm{H} 2 \mathrm{AX}$ showed that the response to radiation was time and dose-dependent in cells from monolayer cultures, whereas cells derived from mammospheres showed little change in $\mathrm{H} 2 \mathrm{AX}$ phosphorylation [34]. In the mammospheres, the low level of $\gamma \mathrm{H} 2 \mathrm{AX}$ after radiation can demonstrate efficient DNA repair as a result of the following: low induction of DNA doublestrand breaks; failure of DNA damage recognition and/or an extremely rapid DNA repair by which the CSCs may be induced into cell cycle progression and proliferation. Induction of the CSCs into a state of cell cycle progression may occur without undergoing cell cycle arrest or apoptosis. The authors also demonstrated that fractionated radiation activates the Notch survival pathway (discussed in detail below), which may have resulted in an increase of the CSC population as well. These findings offered a potential mechanism of cancer cell repopulation during the gaps in radiotherapy.

In the central nervous system, DNA repair is more common in both normal stem cells and CSCs than that in the differentiated and/ or non-CSCs [35]. In glioblastoma cells, CSCs have been shown to be enriched in the fraction of $\mathrm{CD}_{133^{+}}\left(\mathrm{PROM}^{+}\right)$cells, which have reduced sensitivity to radiation-induced apoptosis $[36,37]$. In concert with this finding, Bao et al. showed that $\mathrm{CD} 133^{+}$population in both cell culture and the brains of SCID mice were enriched after ionizing radiation [38]. CD $133^{+}$cells irradiated with 2 Gy had almost the same ability to generate tumors as the non-irradiated $\mathrm{CD} 133^{+}$cells did. Compared to CD133 cells, $\mathrm{CD} 133^{+}$cells isolated from both human glioma xenografts and primary patient glioblastoma specimens showed an activated DNA damage checkpoint upon radiation. This activation could be reversed by debromohymenialdisine (DBH), a specific inhibitor for Chk1 and Chk2 checkpoint transducer kinases [38]. It is well known that Chk1 and Chk2 play a crucial role in the regulation of checkpoint responses to a delay or an arrest in cell cycle leading to the repair of DNA damage [39]. DBH treatment showed a synergistic function with irradiation to disrupt the radioresistance of $\mathrm{CD} 133^{+}$cells (Table 1).

It is also speculated that there is a delay of cell cycle progression via an increase of checkpoint kinases allowing more time to utilize DNA damage repair mechanisms [40]. Similarly, the preclinical profile of AZD7762 (AstraZeneca), a potent inhibitor for Chk kinase family proteins, was described in 2008 [41]. Dose-dependent antitumor activity was observed in multiple xenograft models when AZD7762 was used in combination with DNA-damaging agents, indicating that the checkpoint kinase inhibitors are able to enhance the efficiency of radiotherapy (Table 1). Both the ATM and ATR kinases recognize DNA damage and initiate the cell cycle checkpoint through phosphorylation of many targets $[42,43]$. Chk1 and Chk2 function downstream of ATR and ATM, respectively, in the DNA-damage checkpoint signaling pathway [44-46]. Together, they phosphorylate a variety of effectors, such as p53 and CDC25 phosphatases, leading to cell cycle arrest. Rainey et al. identified CP466722 (Pfizer) by screening a compound library for inhibitors of the ATM kinase [47]. CP466722 inhibited ATM-dependent phosphorylation events and the disruption of ATM function resulted in cell cycle checkpoint defects. The blockade of ATM kinase activity was rapidly and completely removed after withdrawal of CP466722, showing that short-term inhibition of ATM was sufficient to sensitize cells to radiation (Table 1). Thus, drugs such as AZD7762 and CP466722 provide new tools to disrupt constitutive activation of cell cycle checkpoints in CSCs of glioma cells and allow more sensitivity to radiotherapy. Although it is still under investigation whether it is due to enhanced DNA repair mechanisms or a delay in cell cycle progression, CSCs utilize a unique system to ensure efficient DNA repair resulting in radioresistance.

An additional property of CSCs associated with radioresistance is the ability of CSCs to remain in a quiescent state. This property makes them more resistant to cell cycle related agents, including many chemotherapeutic drugs, such as paclitaxel [48], and radiation. In general, proliferating cells are more radiosensitive than quiescent cells [49-51] as the cells in G2/M phase are most radiosensitive while those in late $\mathrm{S}$ phase are most radioresistant. It has been demonstrated that during fractionated radiation therapy, the loss of the bulk tumor cells will cause re-entry into the cell cycle and accelerate the repopulation of CSCs [52]. Abnormal regulation of cyclin-dependent kinase (CDK) pathways controlling cell cycle progression, such as the p16-CDK4RB pathway, may promote the generation and proliferation of CSCs $[53,54]$. Hence, it is of great importance to determine the balance between triggering CSCs into cell cycle and uncontrolled proliferation during and after irradiation.

Survival pathways and its molecular link to CSCs : While different pathways have been shown to be responsible for both CSC self-renewal and radioresistance in multiple cancer settings, there are specific pathways frequently involved that include the Hedgehog $(\mathrm{Hh})$, Notch, and Wnt pathways [55-57].

The Hh pathway is thought to play an important role in regulating CSC proliferation, survival and maintenance [58-62]. Hh was first discovered in Drosophila and it is a highly conserved pathway across multiple organisms. Binding of secreted Hh ligands (Sonic, Desert and Indian) to the Patched (PTCH) receptor on the membrane activates 
Citation: Sun L, Cabarcas SM, Farrar WL (2011) Radioresistance and Cancer Stem Cells: Survival of the Fittest. J Carcinogene Mutagene S1:004. doi:10.4172/2157-2518.S1-004

Hh signaling following the activation of transmembrane protein Smoothened (SMO) and the nuclear translocation of Gli family transcription factors [63,64]. In addition, Gli provides a positive feedback for Hh signaling pathway and its downstream targets include genes controlling cell adhesion, angiogenesis, cell cycle and apoptosis [65]. In human glioma cells, Hh-Gli signaling regulates the expression of stemness genes and the self-renewal of CD $133^{+}$CSCs. Interference of Hh-Gli signaling by cyclopamine or silencing GLI expression by shRNA blocks glioma tumorigenicity in mice, demonstrating that an active Hh signaling pathway is required for glial CSC tumorigenicity [66]. An Hh signaling has also been detected in human breast cancer stem cells characterized as a $\mathrm{CD} 44^{+} / \mathrm{CD} 24^{- \text {-low }} / \mathrm{Lin}^{-}$population $[67,68]$. All of these reveal the essential role of Hh signaling pathway in controlling the behavior of CSCs and offer new therapeutic possibilities. Although the specific role $\mathrm{Hh}$ signaling has in radiation resistance remains an area of active investigation, it is reported that activation of Hh signaling pathway may promote the repopulation of CSCs after radiotherapy, thereby, contributing to both radiation resistance and treatment failure [61]. To determine the role of Hh signaling in therapeutic resistance to radiotherapy, Sims-Mourtada et al. analyzed esophageal tumor samples from 43 radiotherapy resistant cancer patients and showed that $83.7 \%$ had activated $\mathrm{Hh}$ signaling defined by $\mathrm{Hh}$ expression and nuclear GLI localization [61]. Moreover, in esophageal cancer cells, they demonstrated that exogenous Hh ligand stimulation or GLI overexpression provoked a G1-S cell cycle transition by increasing the levels of cyclin D1 expression and Rb phosphorylation, leading to a significant enrichment of radioresistant S-phase fractions [61]. Blocking Hh signaling by either GLI shRNAs or the Hh pathway antagonists cyclopamine and forskolin (Table 1) inhibited the expression of the G1-S checkpoint protein cyclin D1, CDK4 and cell cycle progression. This resulted in the accumulation of cells in the G1 phase and decreased percentage of radioresistant S-phase cells [61]. In an additional study of glioblastoma stem cells, Hh pathway was shown to be dependent on insulin-like growth factor (IGF) signaling in radioresistance [69]. IGF induces the mitogen-activated protein kinase (MAPK) activation, which promotes cell survival by suppressing apoptotic mechanisms and triggering transcription of survival genes, thus, leading to uncontrolled cell proliferation and tumorigenic ability $[70,71]$. These studies demonstrate an important role for Hh signaling in radioresistance.

Notch activation has been found to be crucial in maintaining CSC self-renewal in various niches and is associated with the inhibition of CSC differentiation [72,73]. In mammals, there are four Notch receptor proteins (N1-N4) including a non-covalently associated extracellular subunit (NEC) and a transmembrane subunit (NTM) [74]. The binding of Jagged or Delta-like ligands from an adjacent cell to NEC leads to the cleavage of extracellular NTM and the release of the intracellular portion of NTM, which is dependent on the proteolysis activity of metalloprotease and presenilin/secreatase [75-78]. The intracellular domain of NTM translocates into the nucleus and forms a ternary complex with CSL and MAML family coactivators to regulate their target genes, including the cell cycle regulator p21 [79-82]. The inhibition of the Notch signaling pathway by $\gamma$-secretase inhibitors (GSIs) blocks CSC self-renewal and proliferation in medulloblastoma cells, demonstrating the essential role of Notch pathway in CSCs [83]. Additionally, CSCs in the brain express nestin, which is activated by Notch signaling pathway as well $[84,85]$. Nestin is a class VI intermediate filament protein which is used as a marker to identify neural stem cells (NSCs) and progenitor cells in the developing central nervous system (CNS) [86,87]. Nestin-expressing cells in human cortical glial tumors have the ability to self-renew and differentiate into multiple lineages, suggesting its potential role in maintaining CSC characteristics [88]. Nestin has been detected to be highly expressed in many human primary brain tumors [89,90], especially in CD133+ tumor cells, which could be linked to radiation resistance and the repopulation of CSCs [38]. Notch signaling pathway has also been suggested to activate the EGFR pathway, which could enhance DNA repair capacity and cell survival ability [91]. In other cases, hypoxiamediated expression of HIF1 can interact with Notch signaling and contribute to the maintenance of CSCs in undifferentiated states in a variety of tumor settings [92-95]. For example, in breast cancer, Notch signaling is aberrantly activated by HIF1 and hypoxia-induced Jagged2 activation promotes EMT and the self-renewal of CSCs through the activation of AKT pathway [92]. Additionally, Phillips et al. demonstrated that during fractionated radiation, the breast CSC was enriched and accompanied by radiation-induced Jagged1 expression and Notch1 activation, suggesting the potential role of Notch signaling in radioresistance [34]. Moreover, ectopic expression of the constitutively active Notch intracellular domain enhances the resistance of glioblastoma stem cells to radiation. The disruption of the Notch signaling pathway by $\gamma$-secretase inhibitors (Table 1 ) or knockdown of Notch significantly sensitizes the CSCs to radiation response and reduces the possibilities of xenograft tumor formation by inhibiting the AKT activity [96]. All the evidence above highly suggests that Notch signaling pathway increases the accelerated repopulation and radiation resistance properties of CSCs [97]. However, the exact mechanism(s) by which radioresistance is mediated by Notch signaling is still under investigation.

The activation of the Wnt signaling pathway has been shown to maintain CSC self-renewal in many different ways, including enhancing the proliferation status of CSCs and controlling the capability of CSCs to be associated with their niches $[8,98]$. To date, there are as many as $19 \mathrm{Wnt}$ isoforms reported in human, and they are responsible for the initiation of the signaling cascade by binding to the Frizzled receptor and LRP co-receptor on the membrane [99]. In the absence of Wnt signals, APC, CK1 and GSK3 $\beta$ form a complex to target $\beta$-catenin for phosphorylation and subsequent degradation by the 26 S proteasome [100-102]. The binding of Wnt ligands to the Frizzled and LRP receptors results in the phosphorylation of Dvl and prevents the GSK3 $\beta$ dependent phosphorylation of $\beta$-catenin. $\beta$-catenin is stabilized by dephosphorylation and then translocated into the nucleus where it interacts with the TCF/LEF complex and activates the transcription of target genes, including c-myc, cyclin D1, survivin, VEGF, and the AP-1 transcription complex, all of which are involved in cell cycle progression, proliferation and apoptosis [99]. In a study of breast cancer, the stem cell subpopulation was enriched after radiation and the level of activated $\beta$-catenin was elevated but $\gamma \mathrm{H} 2 \mathrm{AX}$ was resolved quickly, suggesting a role for the $\mathrm{Wnt} / \beta$-catenin signaling cascade and more effective DNA repair in CSCs after radiation [103]. In correlation to this, the $\mathrm{CD} 44^{+} / \mathrm{CD} 24^{-}$population in breast cancer cells has also shown resistance to radiation [104]. Several other links between $\beta$-catenin and DNA damage response have been made as well. Ku70 and PARP-1 compete with $\beta$-catenin for binding to the TCF transcription factors, and upon DNA damage, Ku70 binds to TCF and prevents the formation of an activating transcriptional complex containing $\beta$-catenin. With this model, constitutively active Wnt signaling and stabilized $\beta$-catenin may compete with $\mathrm{Ku} 70$ and overcome DNA damage via LEF/TCF transcription complex 
Citation: Sun L, Cabarcas SM, Farrar WL (2011) Radioresistance and Cancer Stem Cells: Survival of the Fittest. J Carcinogene Mutagene S1:004. doi:10.4172/2157-2518.S1-004

[105]. In addition, survivin, a member of the inhibitors of apoptosis protein (IAP) family, is a target gene of $\beta$-catenin, promotes cellular survival upon apoptotic stimuli [106] and is only expressed in fetal and cancer tissues $[107,108]$. Mechanistically, survivin not only acts as a suppressor of apoptosis through the interference of caspase family proteins [109-111], but promotes cell division and survival by ensuring accurate sister chromatid segregation and microtubule stabilization [112]. The failure to undergo apoptosis and the ability to induce cell proliferation renders the resistance to radiation. The survivin inhibitor, YM155, sensitizes non-small cell lung cancer (NSCLC) cells exposed to radiation (Table 1) [113] and thus, the possibility of targeting survivin is now an attractive option for the development of anti-cancer therapies $[114,115]$. Although the role of Wnt/ $\beta$-catenin signaling in radioresistance of CSCs remains obscure, Wnt signaling activates DNA damage response and leads to tolerance of DNA damage and resistance to radiation. It is hypothesized that this genomic instability may drive the transformation of normal stem cells into CSCs [116].

CSC niches and their microenvironment : The behavior of a cell is determined by its interaction with others and tissue function is a combination of these multicellular behaviors. The microenvironment is particularly important for stem cells because their interaction with stromal elements constitute the stem cell niche [117,118]. The cells located within the niches can regulate the interaction by either direct cell-cell contact or by secreting regulatory molecules that promote stem cell proliferation or inhibit differentiation $[91,117,118]$. Since CSCs have shared normal stem cell characteristics, it is hypothesized that they may reside in specific niches (reviewed in [119]), and are regulated by many stromal components, including cancer-associated fibroblasts and other support cells, extracellular matrix, vasculature and secreted soluble factors [120-124].

It has been suggested that CSC survival can be impacted by their niches following the stress of radiation exposure $[91,103,125,126]$. For example, upon radiation, direct interactions between CSCs and their surrounding cells have been shown to upregulate some anti-apoptotic proteins, like Survivin and BCL-2, and decrease the apoptotic response in prostate cancer cells [127]. Furthermore, knockdown of Survivin by antisense oligonucleotides significantly sensitizes the radiation response of colorectal cancer cells both in vitro and in vivo [128]. Similarly, $\mathrm{CD} 133^{+}$glioma stem cells have been shown to express higher

$\left.\begin{array}{|l|l|l|l|l|}\hline \multicolumn{1}{|c|}{\text { Drugs or Inhibitors }} & \multicolumn{1}{|c|}{\text { Targets }} & \multicolumn{1}{|c|}{\text { Pathways }} & \text { Cancer Models } & \text { Ref. } \\ \hline \text { Debromohymenialdisine } & \text { Chk1/2 } & \begin{array}{l}\text { Cell cycle and } \\ \text { DNA repair }\end{array} & \text { Glioblastoma } & {[37]} \\ \hline \text { AZD7762 (AstraZeneca) } & \text { Chk1/2 } & \begin{array}{l}\text { Cell cycle and } \\ \text { DNA repair }\end{array} & \text { Colon cancer } & {[40]} \\ \hline \text { CP4666722 (Pfizer) } & \text { ATM } & \begin{array}{l}\text { Cell cycle and } \\ \text { DNA repair }\end{array} & \text { Breast cancer } & {[46]} \\ \hline \text { Cyclopamine } & \text { SMO } & \begin{array}{l}\text { Hh signaling } \\ \text { pathway }\end{array} & \begin{array}{l}\text { Esophageal } \\ \text { cancer, } \\ \text { Glioblastoma }\end{array} & {[60]} \\ {[65]}\end{array}\right]$

Table 1: Drugs or inhibitors already available which can sensitize CSCs to radiotherapy. levels of protective autophagy proteins after irradiation, and resistance can be attenuated by inhibition of the expression of these proteins in in vitro sphere-forming assays [126]. In addition, niche-associated Notch pathway was shown to be activated after radiation and resulted in increased symmetric cell division and accelerated repopulation of CSCs [97]. The Notch pathway also plays a crucial role in linking angiogenesis and CSC self-renewal in glioblastoma CSCs. It has been shown that combination treatment of both Notch blockage by DAPT (Table 1) and radiation is more effective than radiation alone in inhibiting the selfrenewal and proliferation in tumor explants [129]. Notch activation has also been suggested to activate some other pathways, such as the EGFR pathway, which could promote DNA repair capability, CSC survival and regeneration kinetics [116,130]. Moreover, CSC niches may also produce survival cytokines, such as EGF, FGF, and VEGF, all of which are responsible for the radioresistance and radioprotection of cancer cells [91].

Medulloblastomas are brain tumors that arise in the cerebellum of children and contain CSCs in the perivascular niche [84,131]. In the mouse models that mimic human medulloblastomas, CSCs in the perivascular niche are nestin-positive and they are able to survive after radiation. Radiation-induced activation of the PI3K/AKT pathway in perivascular stem cells results in p53-dependent cell cycle arrest and the ability to re-enter the cell cycle after $72 \mathrm{~h}$ following radiation, leading to the promotion of radioresistant CSCs. However, the proliferating cells inside the bulk tumor undergo radiation-induced p53-dependent apoptosis, further displaying the importance of the CSC niche located adjacent to the blood vessels [132]. Additionally, the inhibition of Akt phosphorylation by perifosine can sensitize cells in the perivascular region to radiation-induced apoptosis as well (Table 1).

Recent data have shed further light on CSC radioresistance and the role of oxygen and CSCs in the tumor at the time of radiation. The evidence shows this relationship is very important to their radiosensitivity. A state of hypoxia in the niches is necessary to maintain CSCs in an undifferentiated state [133-135], and has been suggested to positively regulate the expression of CSC surface markers (CD133, CD44) and transcription factors (SOX2) [136]. Blazek et al. cultured the Daoy medulloblastoma cell line for 5 days in $2 \%$ oxygen rather than the regular $20 \%$ oxygen and found that the $\mathrm{CD} 133^{+}$sector was enlarged by 1.6 -fold [133]. When treated with radiation from 0 to $10 \mathrm{~Gy}$, the $\mathrm{CD} 133^{+}$Daoy cells were more radioresistant via the $\beta$-parameter of their linear quadratic model than the CD133 counterparts. Interestingly, these $\mathrm{CD} 133^{+}$cells can be significantly converted to the opposite class during incubation in $20 \%$ oxygen for 18 days, which they termed bipotency of $\mathrm{CD}_{133^{+}}$cells [133]. Oxygen is a potent radiosensitizer and can increase the effectiveness of radiation by forming DNA-damaging free radicals [137]. In association with hypoxia, HIF-1 expression is increased in CSCs, which may be protected from oxidative damage with increased ability for DNA damage response and resistance to cell death mechanisms induced by radiotherapy $[38,138,139]$. In addition, TGF- $\beta$, a stem cell related pathway, has been shown to induce HIF1 stabilization [140], suggesting the importance of CSCs to reside in a hypoxic environment by interacting with their niches. Hypoxia is also shown as one of the most important components of therapeutic resistance in some classic biological studies [141].

Angiogenesis is the process resulting in the formation of new blood vessels from the pre-existing vascular network during both normal and pathological development [142]. Angiogenesis is precisely regulated by a balance between pro- and anti-angiogenic factors. The dysregulation 
Citation: Sun L, Cabarcas SM, Farrar WL (2011) Radioresistance and Cancer Stem Cells: Survival of the Fittest. J Carcinogene Mutagene S1:004. doi:10.4172/2157-2518.S1-004

of angiogenesis within tumors produces vessels which are structurally and functionally abnormal, contributing to hypoxia. Hypoxia, in turn, stimulates angiogenesis through HIF- $\alpha$, a crucial transcription factor that activates pro-angiogenic factors, such as VEGF [143]. It has been shown that in glioblastoma cells, the CD133+ CSCs produce higher levels of VEGF in comparison to the CD133 population. The $\mathrm{CD}_{133^{+}}$population induces endothelial cell migration, tube formation and tumor initiation can be blocked by VEGF inhibitors, indicating that CSCs possess increased proangiogenesis ability via VEGF [38]. Thus, this model could serve as a potential target for anti-cancer therapies. Kozin et al. have shown that, in 54A non small lung cancer and U87 glioblastoma models, the dose of radiation required for long-term control of tumors was significantly reduced when using an anti-VEGFR2 antibody (DC101) [144]. More recently, Huber et al. combined SU11657 (an inhibitor of VEGF, PDGF and c-kit) with the chemotherapeutic agent pemetrexed (a multitargeted folate antimetabolite) in radiation therapy both in vitro and in vivo in human A431 epidermoid carcinoma cells. The combination of SU11657 and pemetrexed highly sensitized the cells to radiation and the triple combination was more effective than any single or double treatment
A

Magee Prostate: Normal vs Carcinoma

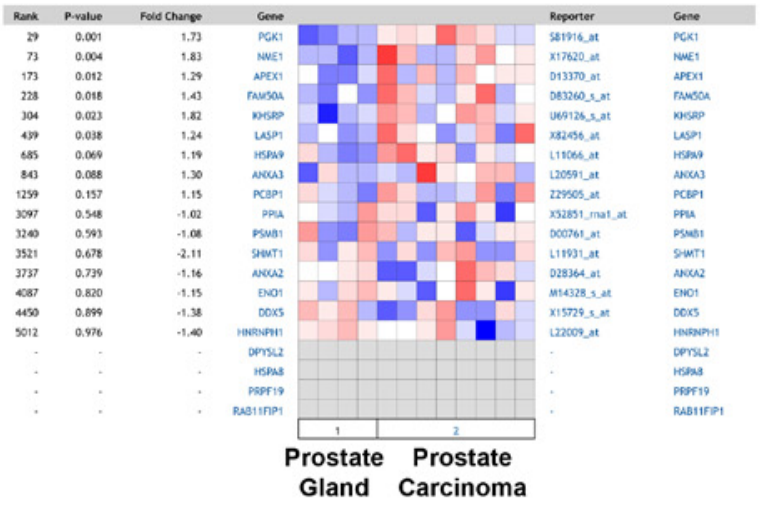

B

\section{Magee Prostate: Metastasis}

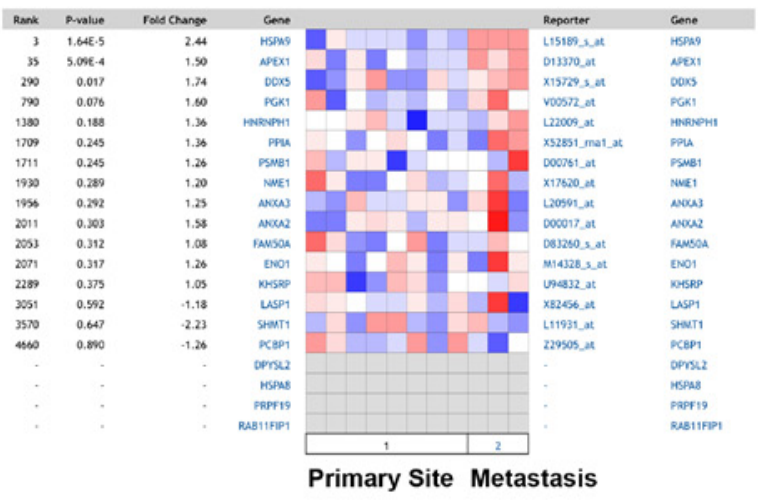

\section{Holzbeierlein Prostate: Metastasis}



Figure 1: Oncomine analysis of radioresistance genes in prostate carcinomas and metastatic tissues. (A) Magee's dataset comparing prostate carcinomas to normal cells. (B) Magee's dataset comparing metastatic tissues to the cells in primary site. (C) Holzbeierlein's dataset comparing metastatic tissues to the cells in primary site. The heat maps represent raw data from the indicated studies comparing the expression level of radioresistance genes in indicated samples. The $p$ value represents Student's $t$ test comparing the two samples. The fold change in expression level, the gene name and the reporter ID from the position on the array are also provided. Most expressed genes are shown in red, while least expressed genes are shown in blue. 
Citation: Sun L, Cabarcas SM, Farrar WL (2011) Radioresistance and Cancer Stem Cells: Survival of the Fittest. J Carcinogene Mutagene S1:004. doi:10.4172/2157-2518.S1-004

[145]. Although the biological basis for the synergetic effects is still not fully understood, it is most likely that antiangiogenic agents can reduce tumor hypoxia and create a 'normalization window for tumor vasculature'. During this period, the tumor cells are more sensitive to radiotherapy and the combination of these multiple therapies provides the best outcome $[143,146]$. Altogether, all the evidence above strongly suggests that CSC niches are an accomplice in giving rise to the radioresistance of CSCs.

\section{Radioresistance in prostate CSCs}

Despite treatment with aggressive chemotherapy, radiotherapy, castration surgery, or combined approaches, prostate cancer is still the third most common cause of death in men of all ages and the most common cause of death in men over 75 years old [147]. Similar to other cancer types, CSCs in prostate cancer are suggested to be responsible for radioresistance during radiotherapy and recurrences afterwards. Recently, Skvortsova et al. established three radiation-resistant cell lines, LNCaP-IRR, Du145-IRR and PC3-IRR from the parental LNCaP, Du145 and PC3 cell lines by repetitive exposure to ionizing radiation [148]. Subsequently, they determined the difference in the proteome profile of parental and IRR cells by 2D difference gel electrophoresis (DIGE), computational image analysis and mass spectrometry (MS) [148]. A list was generated with the differentially modulated proteins in all three IRR cell lines compared to the parental cell lines. The radioresistance signature consists of genes involved in the regulation of cell survival, motility and DNA repair. To further investigate the role of these radioresistance genes in prostate cancer, we applied this list into the Oncomine database to see whether there is any similarity between these genes and clinical samples derived from prostate carcinomas. Firstly, in Magee's dataset, we found elevated expression of these genes in primary prostate carcinoma cells from patients (Figure 1A), suggesting the potential roles of radioresistance genes during carcinogenesis. Secondly, we demonstrate in the same dataset that they are also highly expressed in metastatic tissues, compared to the cells in the primary sites (Figure 1B). A similar trend was also observed with Holzbeierlein's dataset (Figure 1C). CSCs are speculated to be the population responsible for metastasis and radioresistance hence, it is plausible to speculate that patients presenting with metastases will have an increased expression in radioresistant genes. The data derived from the Oncomine database suggest that this speculation is credible as the samples derived from prostate metastatic populations in a bulk tumor have an increase in these genes. Hence, this combined with previous data further supports that CSCs are more radioresistant than their nonmetastatic counterparts [10]. Additionally, CSCs with radioresistance properties are speculated to be responsible for the repopulation of cancer cells after radiotherapy, during which radioresistance genes play a central role, thus, contributing to patient relapse. Importantly, in line with this, we further demonstrate that these radioresistance genes are all increased in patients who have recurrence after one year or five years following radiotherapy (Figure 2A-B). Although the exact relationship between CSCs and the radioresistant signature listed above has not been fully clarified, there is strong evidence derived from Oncomine suggesting an increased expression of radioresistant genes in aggressive prostate cancer tissues and patients with recurrence, disease states that are often attributed to the CSC population.

As shown above, there is a correlation between metastatic cancers and radioresistant genes. Previous studies in our laboratory show that prostatospheres derived from the immortalized $\mathrm{LNCaP}$ cell line and primary patient cell lines PCSC1, PCSC2, PCSC 3 are representative of the CSC population and display the capacity to initiate tumors in vivo [10]. Using Ingenuity Pathway Analysis (IPA) software, we analyzed the genes significantly upregulated in prostatospheres to the total adherent cell population. The genes significantly upregulated were determined by using a whole genome Agilent array analysis that compared prostatospheres to the total adherent cell population

\section{A}

Lapointe Prostate: Recurrence at 1 year

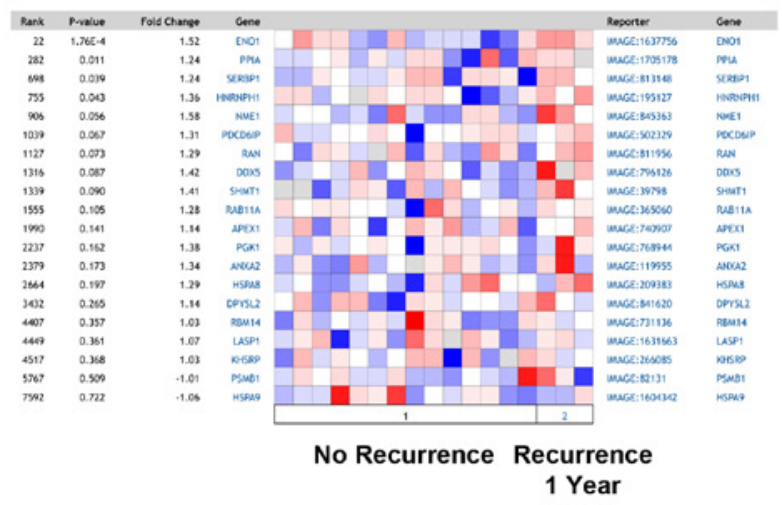

B

Holzbeierlein Prostate: Recurrence at $\mathbf{5}$ years

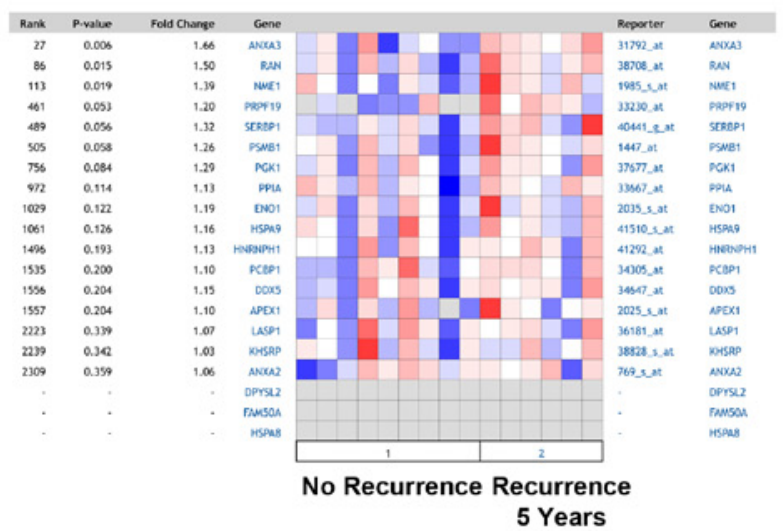

Figure 2: Oncomine analysis of radioresistance genes in patients with recurrence after one year, A: Lapointe's dataset, or five years, B: Holzbeierlein's dataset, following radiotherapy. The heat maps represent raw data from the indicated studies comparing the expression level of radioresistance genes in indicated samples. The $p$ value represents Student's $t$ test comparing the two samples. The fold change in expression level, the gene name and the reporter ID from the position on the array are also provided. Most expressed genes are shown in red, while least expressed genes are shown in blue. 
Citation: Sun L, Cabarcas SM, Farrar WL (2011) Radioresistance and Cancer Stem Cells: Survival of the Fittest. J Carcinogene Mutagene S1:004. doi:10.4172/2157-2518.S1-004

\section{A Pcsc1}

RAN Signaling

Extracellular space

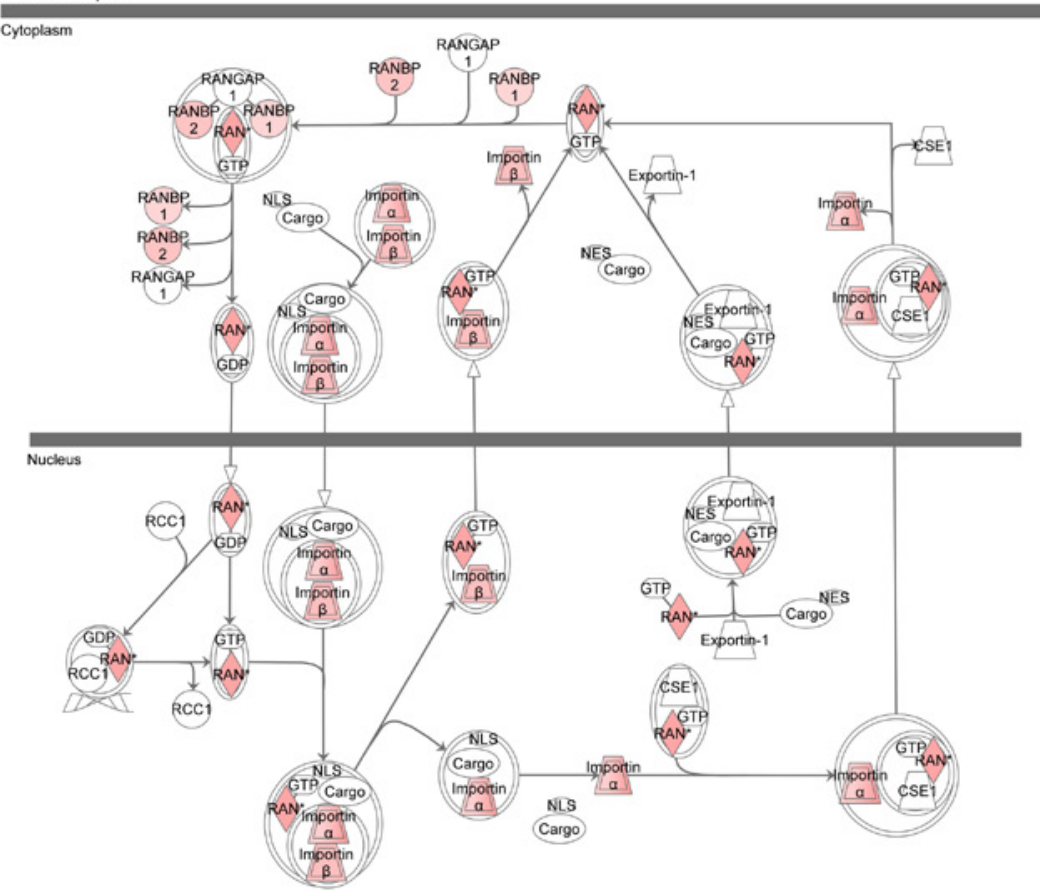

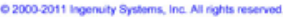

B PCsC3 $^{2}$

RAN Signaling

Extracellular space

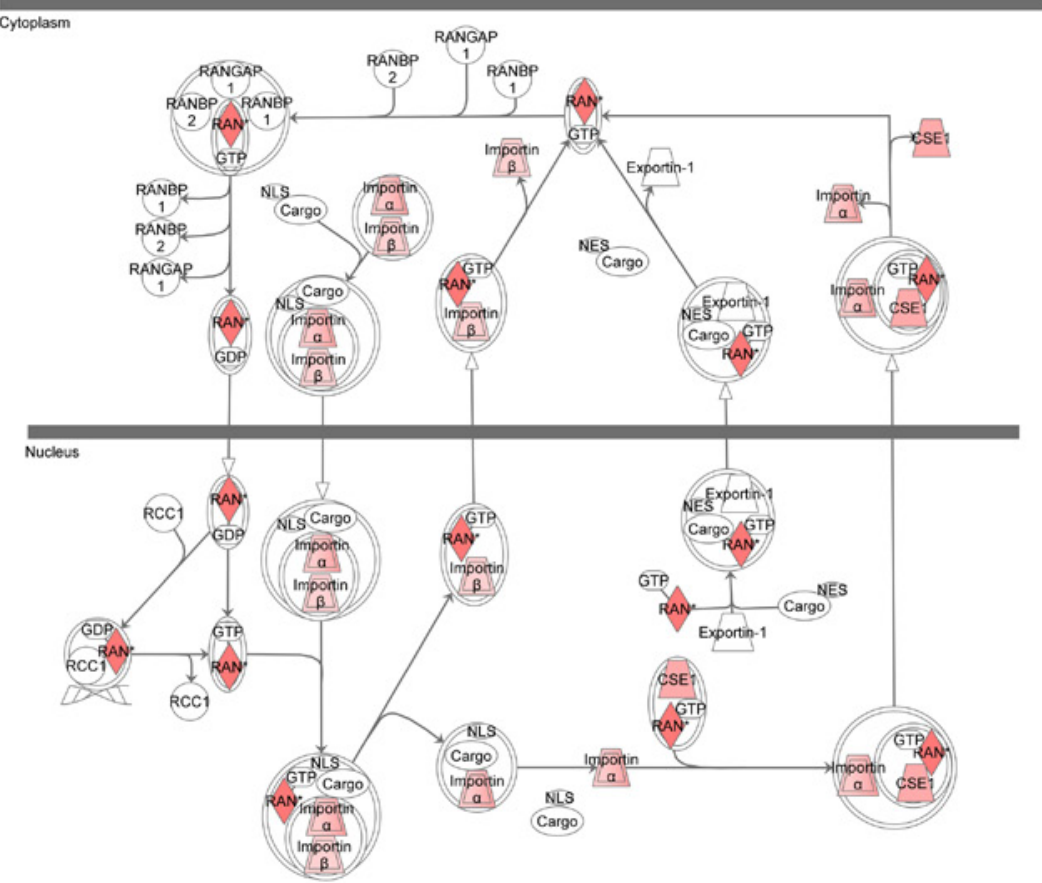

Figure 3: IPA analysis of the array data in our laboratory demonstrates the significant changes of RAN signaling pathway in prostatospheres. Genes highlighted in red suggest the significant increase of expression in prostatospheres compared to adherent cells. In PCSC1 (A) and PCSC3 (B) primary patient cell lines, prostatospheres have an increase of gene expression in RAN signaling pathway. Each symbol stands for a molecule with different function as follows: diamond: enzyme; ellipse: transcription regulator; trapezium: transporter; circle: others. Regular arrows mean "acts on" and arrows with outlined triangles stand for "translocates to". 
Citation: Sun L, Cabarcas SM, Farrar WL (2011) Radioresistance and Cancer Stem Cells: Survival of the Fittest. J Carcinogene Mutagene S1:004. doi:10.4172/2157-2518.S1-004

Page 8 of 12

\begin{tabular}{|l|l|}
\hline \multicolumn{2}{|l|}{ PCSC1 RAN Signaling } \\
\hline \multicolumn{1}{|l|}{ RAN Signaling Genes } & Fold-Change (Prostatospheres vs Adherent) \\
\hline KPNA1 & 1.419 \\
\hline KPNA2 & 2.698 \\
\hline KPNA6 & 1.238 \\
\hline RAN & 2.338 \\
\hline RANBP1 & 1.085 \\
\hline RANBP2 & 1.556 \\
\hline RCC1 & 1.701 \\
\hline TNP01 & 1.681 \\
\hline PCSC3 RAN Signaling & \\
\hline RAN Signaling Genes & Fold-Change (Prostatospheres vs Adherent) \\
\hline CSE1L & 1.908 \\
\hline KPNA2 & 2.169 \\
\hline KPNA3 & 1.179 \\
\hline KPNA4 & 2.078 \\
\hline RAN & 3.065 \\
\hline RCC1 & 1.1520 \\
\hline TNP01 & 1.052 \\
\hline
\end{tabular}

Table 2: The molecules involved in RAN signaling pathways which were elevated in prostatospheres.

(Cabarcas et al., manuscript under review). Using this specific gene set, we found that the RAN signaling pathway is one of the top upregulated pathways in prostatospheres for two primary patient cell lines, PCSC1
(Figure 3A) and PCSC3 (Figure 3B). The molecules involved in this pathway which were expressed significantly higher in prostatospheres compared to adherent cells are organized in Table 2. In line with this, RAN is also included in the radioresistant gene list we used to interrogate the Oncomine database. RAN (ras-related nuclear protein), a member of the RAS superfamily, is a small GTP binding protein that is essential for the translocation of RNA and proteins through the nuclear pore complex. RAN is described as a downstream gene of the PI3K/AKT signaling pathway [149] and is also involved in DNA synthesis and cell cycle progression. Mutation of RAN disrupts DNA synthesis [150], and a constitutively activated RAN mutant is sufficient to transform NIH-3T3 cells, which form tumors in mice, in an mTOR and EGFR dependent manner [151]. Moreover, in aggressive ovarian cancer cell lines, downregulation of RAN expression inhibits cellular proliferation by inducing a caspase- 3 dependent apoptosis, suggesting an essential role of RAN in ovarian cancer [152]. Although the role of RAN in prostate CSCs needs to be further elucidated, we identified increased radioresistance gene expression in a prostate CSC population and hence, it will be very interesting to further study the mechanisms of radioresistance and how to sensitize and target CSCs in radiotherapies.

\section{Conclusion}

In the past few years, the existence and nature of CSCs in different tumor settings has been a debatable topic in cancer research field. CSCs represent a specific population inside the bulk tumor and only a low number of CSCs are able to form colonies in vitro and initiate
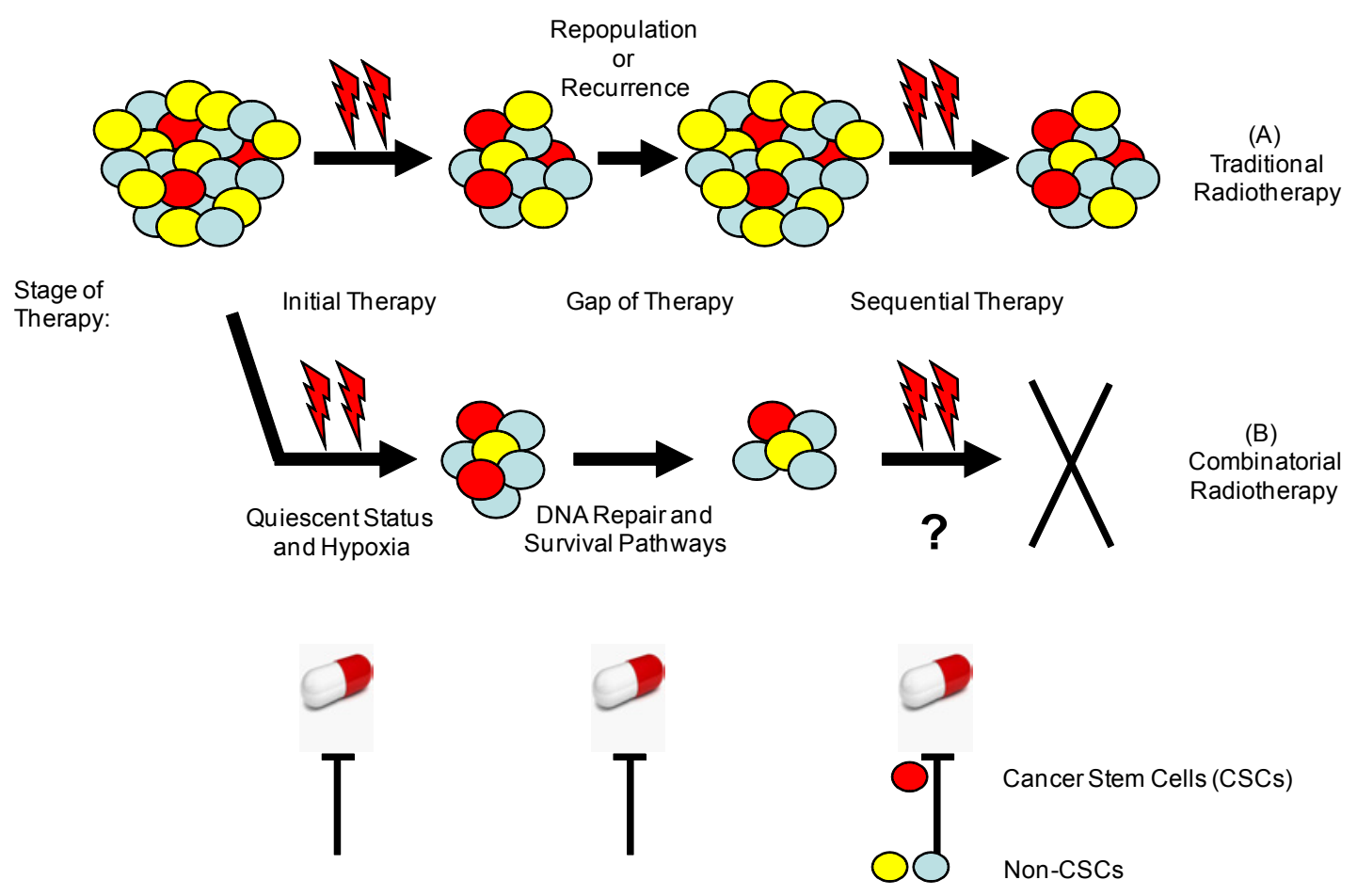

Drugs or inhibitors that can sensitize CSCs to radiotherapy

Figure 4: A proposed model for radiotherapy approaches that can target CSCs. (A) In traditional radiotherapy, the bulk tumor shrinks after initial radiation, but the cancer cells repopulate during the gaps of radiotherapy, leading to patient relapse. (B) In combinatorial radiotherapy, drugs or inhibitors can be used to sensitize CSCs to radiation and enhance the outcome of therapy. During initial radiotherapy, the main targets may be the quiescent status of CSCs and hypoxia. Afterwards, the DNA repair mechanisms and the survival pathways become more dominant and can be targeted to prevent the repopulation of CSCs. 
Citation: Sun L, Cabarcas SM, Farrar WL (2011) Radioresistance and Cancer Stem Cells: Survival of the Fittest. J Carcinogene Mutagene S1:004. doi:10.4172/2157-2518.S1-004

tumors in vivo. CSCs are relatively resistant to radiotherapy and thus, many studies have focused on the pathways and niches associated with CSC radioresistance. However, different CSC resistance pathways may play roles at different stages during fractionated radiotherapy. Therefore, it will be necessary to take into account the dynamics of CSC radioresistance mechanisms at different stages during radiotherapy, and the timing and duration of therapeutic strategies must be defined. For example, at the beginning of radiotherapy, the most likely mechanisms of CSC resistance are their quiescent status and hypoxia. After initial therapy, DNA repair mechanisms, as well as survival pathways may become more dominant for the accelerated repopulation as CSCs are induced into cell cycle progression and proliferation. On the other hand, addition of chemotherapeutic agents during radiotherapy may be another effective strategy to sensitize CSCs to radiation (summarized in Figure 4). Similar combination approaches are now underway to strengthen the radiotherapeutic outcomes. As previously demonstrated, drugs and inhibitors are already available which can sensitize the CSCs to radiotherapy (Table 1). It would be of great interest to further investigate the effect of these drugs on CSC pathways and their ability to radiosensitize CSCs and prevent metastasis and relapse. Although it is still not clear whether these approaches directly contribute to CSC radioresistance mechanisms, we believe these data point out a new direction for the development of newly targeted therapies to overcome CSC radioresistance.

\section{Acknowledgements}

This project has been funded in whole or in part with federal funds from the National Cancer Institute, National Institutes of Health, under contract no. HHSN261200800001E. The content of this publication does not necessarily reflect the views or policies of the Department of Health and Human Services, nor does mention of trade names, commercial products, or organizations imply endorsement by the US Government. This Research was supported in part by the Intramural Research Program of the $\mathrm{NIH}$, National Cancer Institute, Center for Cancer Research.

\section{References}

1. Jemal A, Siegel R, Xu J, Ward E (2010) Cancer statistics, 2010. CA Cancer J Clin 60: 277-300.

2. Dick JE (2008) Stem cell concepts renew cancer research. Blood 112: $4793-$ 4807.

3. Crea F, Duhagon MA, Farrar WL, Danesi R (2011) Pharmacogenomics and cancer stem cells: a changing landscape. Trends Pharmacol Sci.

4. Lapidot T, Sirard C, Vormoor J, Murdoch B, Hoang T, et al. (1994) A cell initiating human acute myeloid leukaemia after transplantation into SCID mice. Nature 367: 645-648

5. Ailles LE, Weissman IL (2007) Cancer stem cells in solid tumors. Curr Opin Biotechnol 18: 460-466.

6. O'Brien CA, Kreso A, Jamieson CH (2010) Cancer stem cells and self-renewal. Clin Cancer Res 16: 3113-3120.

7. Sengupta A, Cancelas JA (2010) Cancer stem cells: a stride towards cancer cure. J Cell Physiol 225: 7-14.

8. Hurt EM, Kawasaki BT, Klarmann GJ, Thomas SB, Farrar WL (2008) CD44+ CD24(-) prostate cells are early cancer progenitor/stem cells that provide a model for patients with poor prognosis. Br J Cancer 98: 756-765.

9. Collins AT, Berry PA, Hyde C, Stower MJ, Maitland NJ (2005) Prospective identification of tumorigenic prostate cancer stem cells. Cancer Res 65: 1094610951.

10. Duhagon MA, Hurt EM, Sotelo-Silveira JR, Zhang X, Farrar WL (2010) Genomic profiling of tumor initiating prostatospheres. BMC Genomics 11: 324.

11. Dontu G, Abdallah WM, Foley JM, Jackson KW, Clarke MF, et al. (2003) In vitro propagation and transcriptional profiling of human mammary stem/progenitor cells. Genes Dev 17: 1253-1270.
12. Gaviraghi M, Tunici P, Valensin S, Rossi M, Giordano C, et al. (2010) Pancreatic cancer spheres are more than just aggregates of stem marker-positive cells. Biosci Rep 31: 45-55.

13. Gou S, Liu T, Wang C, Yin T, Li K, et al. (2007) Establishment of clona colony-forming assay for propagation of pancreatic cancer cells with stem cell properties. Pancreas 34: 429-435.

14. Klarmann GJ, Hurt EM, Mathews LA, Zhang X, Duhagon MA, et al. (2009) Invasive prostate cancer cells are tumor initiating cells that have a stem cell-like genomic signature. Clin Exp Metastasis 26: 433-446.

15. Yu SC, Bian XW (2009) Enrichment of cancer stem cells based on heterogeneity of invasiveness. Stem Cell Rev 5: 66-71.

16. Reya T, Morrison SJ, Clarke MF, Weissman IL (2001) Stem cells, cancer, and cancer stem cells. Nature 414: 105-111.

17. Visvader JE, Lindeman GJ (2008) Cancer stem cells in solid tumours accumulating evidence and unresolved questions. Nat Rev Cancer 8: 755-768.

18. Ralhan R, Kaur J, Kreienberg R, Wiesmuller L (2007) Links between DNA double strand break repair and breast cancer: accumulating evidence from both familial and nonfamilial cases. Cancer Lett 248: 1-17.

19. Tichy ED, Stambrook PJ (2008) DNA repair in murine embryonic stem cells and differentiated cells. Exp Cell Res 314: 1929-1936.

20. Kinsella TJ (2009) Coordination of DNA mismatch repair and base excision repair processing of chemotherapy and radiation damage for targeting resistant cancers. Clin Cancer Res 15: 1853-1859.

21. Vaish M (2007) Mismatch repair deficiencies transforming stem cells into cancer stem cells and therapeutic implications. Mol Cancer 6: 26.

22. Sengupta S, Harris CC (2005) p53: traffic cop at the crossroads of DNA repair and recombination. Nat Rev Mol Cell Biol 6: 44-55.

23. Dalhus B, Laerdahl JK, Backe PH, Bjoras M (2009) DNA base repairrecognition and initiation of catalysis. FEMS Microbiol Rev 33: 1044-1078.

24. Mathews LA, Cabarcas SM, Farrar WL (2011) DNA repair: the culprit for tumorinitiating cell survival. Cancer Metastasis Rev 30: 185-197.

25. Dasika GK, Lin SC, Zhao S, Sung P, Tomkinson A, et al. (1999) DNA damageinduced cell cycle checkpoints and DNA strand break repair in development and tumorigenesis. Oncogene 18: 7883-7899.

26. Elledge SJ (1996) Cell cycle checkpoints: preventing an identity crisis. Science 274: 1664-1672.

27. Wang JY (1998) Cellular responses to DNA damage. Curr Opin Cell Biol 10 240-247.

28. Weinert T (1998) DNA damage and checkpoint pathways: molecular anatomy and interactions with repair. Cell 94: 555-558.

29. Hartwell LH, Kastan MB (1994) Cell cycle control and cancer. Science 266 1821-1828.

30. Lengauer C, Kinzler KW, Vogelstein B (1997) Genetic instability in colorectal cancers. Nature 386: 623-627.

31. Olive PL (2004) Detection of DNA damage in individual cells by analysis of histone H2AX phosphorylation. Methods Cell Biol 75: 355-373.

32. Sedelnikova OA, Pilch DR, Redon C, Bonner WM (2003) Histone H2AX in DNA damage and repair. Cancer Biol Ther 2: 233-235.

33. Kuhne M, Riballo E, Rief N, Rothkamm K, Jeggo PA, et al. (2004) A doublestrand break repair defect in ATM-deficient cells contributes to radiosensitivity. Cancer Res 64: 500-508

34. Phillips TM, McBride WH, Pajonk F (2006) The response of CD24(-/low) CD44+ breast cancer-initiating cells to radiation. J Natl Cancer Inst 98: 17771785.

35. Frosina G (2009) DNA repair and resistance of gliomas to chemotherapy and radiotherapy. Mol Cancer Res 7: 989-999.

36. Singh SK, Hawkins C, Clarke ID, Squire JA, Bayani J, et al. (2004) Identification of human brain tumour initiating cells. Nature 432: 396-401. 
Citation: Sun L, Cabarcas SM, Farrar WL (2011) Radioresistance and Cancer Stem Cells: Survival of the Fittest. J Carcinogene Mutagene S1:004. doi:10.4172/2157-2518.S1-004

37. Hemmati HD, Nakano I, Lazareff JA, Masterman-Smith M, Geschwind DH, et al. (2003) Cancerous stem cells can arise from pediatric brain tumors. Proc Natl Acad Sci U S A 100: 15178-15183.

38. Bao S, Wu Q, McLendon RE, Hao Y, Shi Q, et al. (2006) Glioma stem cells promote radioresistance by preferential activation of the DNA damage response. Nature 444: 756-760.

39. Sancar A, Lindsey-Boltz LA, Unsal-Kacmaz K, Linn S (2004) Molecular mechanisms of mammalian DNA repair and the DNA damage checkpoints. Annu Rev Biochem 73: 39-85.

40. Ropolo M, Daga A, Griffero F, Foresta M, Casartelli G, et al. (2009) Comparative analysis of DNA repair in stem and nonstem glioma cell cultures. Mol Cancer Res 7: 383-392.

41. Zabludoff SD, Deng C, Grondine MR, Sheehy AM, Ashwell S, et al. (2008) AZD7762, a novel checkpoint kinase inhibitor, drives checkpoint abrogation and potentiates DNA-targeted therapies. Mol Cancer Ther 7: 2955-2966.

42. Cimprich KA, Cortez D (2008) ATR: an essential regulator of genome integrity. Nat Rev Mol Cell Biol 9: 616-627.

43. Reinhardt HC, Yaffe MB (2009) Kinases that control the cell cycle in response to DNA damage: Chk1, Chk2, and MK2. Curr Opin Cell Biol 21: 245-255

44. Shiloh Y (2001) ATM and ATR: networking cellular responses to DNA damage. Curr Opin Genet Dev 11: 71-77.

45. Melo J, Toczyski D (2002) A unified view of the DNA-damage checkpoint. Curr Opin Cell Biol 14: 237-245

46. Gatei M, Sloper K, Sorensen C, Syljuasen R, Falck J, et al. (2003) Ataxiatelangiectasia-mutated (ATM) and NBS1-dependent phosphorylation of Chk1 on Ser-317 in response to ionizing radiation. J Biol Chem 278: 14806-14811.

47. Rainey MD, Charlton ME, Stanton RV, Kastan MB (2008) Transient inhibition of ATM kinase is sufficient to enhance cellular sensitivity to ionizing radiation. Cancer Res 68: 7466-7474.

48. Tanei T, Morimoto K, Shimazu K, Kim SJ, Tanji Y, et al. (2009) Association of breast cancer stem cells identified by aldehyde dehydrogenase 1 expression with resistance to sequential Paclitaxel and epirubicin-based chemotherapy for breast cancers. Clin Cancer Res 15: 4234-4241.

49. Masunaga S, Ono K, Abe M (1991) A method for the selective measurement of the radiosensitivity of quiescent cells in solid tumors--combination of immunofluorescence staining to BrdU and micronucleus assay. Radiat Res 125: 243-247.

50. Sweigert SE, Eguchi-Kasai K, Warters RL, Dethlefsen LA (1989) Repair of DNA single- and double-strand breaks in proliferating and quiescent murine tumor cells. Int J Radiat Biol 56: 253-264.

51. Ahsan A, Hiniker SM, Davis MA, Lawrence TS, Nyati MK (2009) Role of cell cycle in epidermal growth factor receptor inhibitor-mediated radiosensitization. Cancer Res 69: 5108-5114.

52. Withers HR, Taylor JM, Maciejewski B (1988) The hazard of accelerated tumor clonogen repopulation during radiotherapy. Acta Oncol 27: 131-146.

53. Hulleman E, Helin K (2005) Molecular mechanisms in gliomagenesis. Adv Cancer Res 94: 1-27.

54. Boyer MJ, Cheng T (2008) The CDK inhibitors: potential targets for therapeutic stem cell manipulations. Gene Ther 15: 117-125.

55. Molofsky AV, Pardal R, Morrison SJ (2004) Diverse mechanisms regulate stem cell self-renewal. Curr Opin Cell Biol 16: 700-707.

56. Henrique D, Hirsinger E, Adam J, Le Roux I, Pourquie O, et al. (1997) Maintenance of neuroepithelial progenitor cells by Delta-Notch signalling in the embryonic chick retina. Curr Biol 7: 661-670.

57. Crea F, Mathews LA, Farrar WL, Hurt EM (2009) Targeting prostate cancer stem cells. Anticancer Agents Med Chem 9: 1105-1113.

58. Berman DM, Karhadkar SS, Maitra A, Montes De Oca R, Gerstenblith MR, et al. (2003) Widespread requirement for Hedgehog ligand stimulation in growth of digestive tract tumours. Nature 425: 846-851.
59. Evangelista M, Tian H, de Sauvage FJ (2006) The hedgehog signaling pathway in cancer. Clin Cancer Res 12: 5924-5928.

60. Lai K, Kaspar BK, Gage FH, Schaffer DV (2003) Sonic hedgehog regulates adult neural progenitor proliferation in vitro and in vivo. Nat Neurosci 6: 21-27.

61. Sims-Mourtada J, Izzo JG, Apisarnthanarax S, Wu TT, Malhotra U, et al. (2006) Hedgehog: an attribute to tumor regrowth after chemoradiotherapy and a targe to improve radiation response. Clin Cancer Res 12: 6565-6572.

62. Karhadkar SS, Bova GS, Abdallah N, Dhara S, Gardner D, et al. (2004) Hedgehog signalling in prostate regeneration, neoplasia and metastasis. Nature 431: 707-712.

63. Ingham PW, McMahon AP (2001) Hedgehog signaling in animal development: paradigms and principles. Genes Dev 15: 3059-3087.

64. Ruel L, Rodriguez R, Gallet A, Lavenant-Staccini L, Therond PP (2003) Stability and association of Smoothened, Costal2 and Fused with Cubitus interruptus are regulated by Hedgehog. Nat Cell Biol 5: 907-913

65. Yoon JW, Kita Y, Frank DJ, Majewski RR, Konicek BA, et al. (2002) Gene expression profiling leads to identification of GLI1-binding elements in targe genes and a role for multiple downstream pathways in GLI1-induced cell transformation. J Biol Chem 277: 5548-5555.

66. Clement V, Sanchez P, de Tribolet N, Radovanovic I, Ruiz i Altaba A (2007) HEDGEHOG-GLI1 signaling regulates human glioma growth, cancer stem cell self-renewal, and tumorigenicity. Curr Biol 17: 165-172.

67. Liu SL, Dontu G, Wicha MS (2005) Mammary stem cells, self-renewa pathways, and carcinogenesis. Breast Cancer Res 7: 86-95.

68. Liu SL, Dontu G, Mantle ID, Patel S, Ahn NS, et al. (2006) Hedgehog signaling and Bmi-1 regulate self-renewal of normal and malignant human mammary stem cells. Cancer Research 66: 6063-6071.

69. Hsieh A, Ellsworth R, Hsieh D (2011) Hedgehog/GLI1 regulates IGF dependen malignant behaviors in glioma stem cells. J Cell Physiol 226: 1118-1127.

70. Bonni A, Brunet A, West AE, Datta SR, Takasu MA, et al. (1999) Cell surviva promoted by the Ras-MAPK signaling pathway by transcription-dependent and -independent mechanisms. Science 286: 1358-1362.

71. Dhillon AS, Hagan S, Rath O, Kolch W (2007) MAP kinase signalling pathways in cancer. Oncogene 26: 3279-3290.

72. Hittelman WN, Liao Y, Wang L, Milas L (2010) Are cancer stem cells radioresistant. Future Oncol 6: 1563-1576.

73. Weng AP, Aster JC (2004) Multiple niches for Notch in cancer: context is everything. Curr Opin Genet Dev 14: 48-54.

74. Rand MD, Grimm LM, Artavanis-Tsakonas S, Patriub V, Blacklow SC, et al. (2000) Calcium depletion dissociates and activates heterodimeric notch receptors. Mol Cell Biol 20: 1825-1835.

75. Brou C, Logeat F, Gupta N, Bessia C, LeBail O, et al. (2000) A novel proteolytic cleavage involved in Notch signaling: the role of the disintegrin-metalloprotease TACE. Mol Cell 5: 207-216.

76. Mumm JS, Schroeter EH, Saxena MT, Griesemer A, Tian X, et al. (2000) A ligand-induced extracellular cleavage regulates gamma-secretase-like proteolytic activation of Notch1. Mol Cell 5: 197-206.

77. De Strooper B, Annaert W, Cupers P, Saftig P, Craessaerts K, et al. (1999) A presenilin-1-dependent gamma-secretase-like protease mediates release of Notch intracellular domain. Nature 398: 518-522.

78. Okochi M, Steiner H, Fukumori A, Tanii H, Tomita T, et al. (2002) Presenilins mediate a dual intramembranous gamma-secretase cleavage of Notch-1. EMBO J 21: 5408-5416.

79. Fortini ME, Artavanis-Tsakonas S (1994) The suppressor of hairless protein participates in notch receptor signaling. Cell 79: 273-282.

80. Jarriault S, Brou C, Logeat F, Schroeter EH, Kopan R, et al. (1995) Signalling downstream of activated mammalian Notch. Nature 377: 355-358

81. Christensen S, Kodoyianni V, Bosenberg M, Friedman L, Kimble J (1996) lag 1 , a gene required for lin-12 and glp-1 signaling in Caenorhabditis elegans, is 
Citation: Sun L, Cabarcas SM, Farrar WL (2011) Radioresistance and Cancer Stem Cells: Survival of the Fittest. J Carcinogene Mutagene S1:004. doi:10.4172/2157-2518.S1-004

homologous to human CBF1 and Drosophila Su(H). Development 122: 13731383.

82. Wu L, Aster JC, Blacklow SC, Lake R, Artavanis-Tsakonas S, et al. (2000) MAML1, a human homologue of Drosophila mastermind, is a transcriptional co-activator for NOTCH receptors. Nat Genet 26: 484-489.

83. Fan X, Matsui W, Khaki L, Stearns D, Chun J, et al. (2006) Notch pathway inhibition depletes stem-like cells and blocks engraftment in embryonal brain tumors. Cancer Res 66: 7445-7452.

84. Calabrese C, Poppleton H, Kocak M, Hogg TL, Fuller C, et al. (2007) A perivascular niche for brain tumor stem cells. Cancer Cell 11: 69-82.

85. Shih AH, Holland EC (2006) Notch signaling enhances nestin expression in gliomas. Neoplasia 8: 1072-1082.

86. Wiese C, Rolletschek A, Kania G, Blyszczuk P, Tarasov KV, et al. (2004) Nestin expression--a property of multi-lineage progenitor cells. Cell Mol Life Sci 61: $2510-2522$

87. Lendahl U, Zimmerman LB, McKay RD (1990) CNS stem cells express a new class of intermediate filament protein. Cell 60: 585-595.

88. Ignatova TN, Kukekov VG, Laywell ED, Suslov ON, Vrionis FD, et al. (2002) Human cortical glial tumors contain neural stem-like cells expressing astroglial and neuronal markers in vitro. Glia 39: 193-206.

89. Ehrmann J, Kolar Z, Mokry J (2005) Nestin as a diagnostic and prognostic marker: immunohistochemical analysis of its expression in different tumours. $\mathrm{J}$ Clin Pathol 58: 222-223.

90. Schiffer D, Manazza A, Tamagno I (2006) Nestin expression in neuroepithelial tumors. Neurosci Lett 400: 80-85.

91. Barcellos-Hoff MH, Park C, Wright EG (2005) Radiation and the microenvironment - tumorigenesis and therapy. Nat Rev Cancer 5: 867-875.

92. Xing F, Okuda H, Watabe M, Kobayashi A, Pai SK, et al. (2011) Hypoxiainduced Jagged2 promotes breast cancer metastasis and self-renewal of cancer stem-like cells. Oncogene

93. Wang Y, Liu Y, Malek SN, Zheng P (2011) Targeting HIF1alpha Eliminates Cancer Stem Cells in Hematological Malignancies. Cell Stem Cell 8: 399-411.

94. Yeung TM, Gandhi SC, Bodmer WF (2011) Hypoxia and lineage specification of cell line-derived colorectal cancer stem cells. Proc Natl Acad Sci U S A 108: $4382-4387$.

95. Bar EE, Lin A, Mahairaki V, Matsui W, Eberhart CG (2010) Hypoxia increases the expression of stem-cell markers and promotes clonogenicity in glioblastoma neurospheres. Am J Pathol 177: 1491-1502.

96. Wang J, Wakeman TP, Lathia JD, Hjelmeland AB, Wang XF, et al. (2010) Notch promotes radioresistance of glioma stem cells. Stem Cells 28: 17-28.

97. Gupta R, Vyas P, Enver T (2009) Molecular targeting of cancer stem cells. Cell Stem Cell 5: 125-126.

98. Takebe N, Ivy SP (2010) Controversies in cancer stem cells: targeting embryonic signaling pathways. Clin Cancer Res 16: 3106-3112.

99. Yao H, Ashihara E, Maekawa T (2011) Targeting the Wnt/beta-catenin signaling pathway in human cancers. Expert Opin Ther Targets

100. Liu C, Li Y, Semenov M, Han C, Baeg GH, et al. (2002) Control of beta-catenin phosphorylation/degradation by a dual-kinase mechanism. Cell 108: 837-847.

101. Amit S, Hatzubai A, Birman Y, Andersen JS, Ben-Shushan E, et al. (2002) Axin-mediated CKI phosphorylation of beta-catenin at Ser 45: a molecular switch for the Wnt pathway. Genes Dev 16: 1066-1076.

102. Kitagawa M, Hatakeyama S, Shirane M, Matsumoto M, Ishida N, et al. (1999) An F-box protein, FWD1, mediates ubiquitin-dependent proteolysis of betacatenin. EMBO J 18: 2401-2410.

103. Woodward WA, Chen MS, Behbod F, Alfaro MP, Buchholz TA, et al. (2007) WNT/beta-catenin mediates radiation resistance of mouse mammary progenitor cells. Proc Natl Acad Sci U S A 104: 618-623.

104. Dave B, Chang J (2009) Treatment resistance in stem cells and breast cancer J Mammary Gland Biol Neoplasia 14: 79-82.
105. Idogawa M, Masutani M, Shitashige M, Honda K, Tokino T, et al. (2007) Ku70 and poly(ADP-ribose) polymerase-1 competitively regulate beta-catenin and T-cell factor-4-mediated gene transactivation: possible linkage of DNA damage recognition and Wnt signaling. Cancer Res 67: 911-918.

106.Zhang T, Otevrel T, Gao Z, Ehrlich SM, Fields JZ, et al. (2001) Evidence that APC regulates survivin expression: a possible mechanism contributing to the stem cell origin of colon cancer. Cancer Res 61: 8664-8667.

107.Wang W, Luo H, Wang A (2006) Expression of survivin and correlation with PCNA in osteosarcoma. J Surg Oncol 93: 578-584.

108. Johnson ME, Howerth EW (2004) Survivin: a bifunctional inhibitor of apoptosis protein. Vet Pathol 41: 599-607.

109. Shin S, Sung BJ, Cho YS, Kim HJ, Ha NC, et al. (2001) An anti-apoptotic protein human survivin is a direct inhibitor of caspase-3 and -7 . Biochemistry 40: 1117-1123.

110. Tamm I, Wang Y, Sausville E, Scudiero DA, Vigna N, et al. (1998) IAP-family protein survivin inhibits caspase activity and apoptosis induced by Fas (CD95), Bax, caspases, and anticancer drugs. Cancer Res 58: 5315-5320.

111.Dohi T, Beltrami E, Wall NR, Plescia J, Altieri DC (2004) Mitochondrial survivin inhibits apoptosis and promotes tumorigenesis. J Clin Invest 114: 1117-1127.

112. Yang D, Welm A, Bishop JM (2004) Cell division and cell survival in the absence of survivin. Proc Natl Acad Sci U S A 101: 15100-15105.

113. Iwasa T, Okamoto I, Suzuki M, Nakahara T, Yamanaka K, et al. (2008) Radiosensitizing effect of YM155, a novel small-molecule survivin suppressant, in non-small cell lung cancer cell lines. Clin Cancer Res 14: 6496-6504.

114. Kanwar JR, Kamalapuram SK, Kanwar RK (2010) Targeting survivin in cancer: patent review. Expert Opin Ther Pat 20: 1723-1737.

115. Ryan BM, O'Donovan N, Duffy MJ (2009) Survivin: a new target for anticancer therapy. Cancer Treat Rev 35: 553-562.

116. Ischenko I, Seeliger H, Schaffer M, Jauch KW, Bruns CJ (2008) Cancer stem cells: how can we target them. Curr Med Chem 15: 3171-3184.

117. Schofield R (1978) The relationship between the spleen colony-forming cell and the haemopoietic stem cell. Blood Cells 4: 7-25.

118. Whetton AD, Graham GJ (1999) Homing and mobilization in the stem cell niche. Trends Cell Biol 9: 233-238.

119. Cabarcas SM, Mathews LA, Farrar WL (2011) The Cancer Stem Cell Niche there goes the neighborhood. International Journal of Cancer In press.

120. Morrison SJ, Spradling AC (2008) Stem cells and niches: mechanisms that promote stem cell maintenance throughout life. Cell 132: 598-611.

121. Voog J, Jones DL (2010) Stem cells and the niche: a dynamic duo. Cell Stem Cell 6: 103-115.

122. Crosnier C, Stamataki D, Lewis J (2006) Organizing cell renewal in the intestine: stem cells, signals and combinatorial control. Nat Rev Genet 7: 349359.

123. Williams DA, Cancelas JA (2006) Leukaemia: niche retreats for stem cells Nature 444: 827-828.

124. Jones DL, Wagers AJ (2008) No place like home: anatomy and function of the stem cell niche. Nat Rev Mol Cell Biol 9: 11-21.

125. Ghotra VP, Puigvert JC, Danen EH (2009) The cancer stem cell microenvironment and anti-cancer therapy. Int J Radiat Biol 85: 955-962.

126. Lomonaco SL, Finniss S, Xiang C, Decarvalho A, Umansky F, et al. (2009) The induction of autophagy by gamma-radiation contributes to the radioresistance of glioma stem cells. Int J Cancer 125: 717-722.

127. Bromfield GP, Meng A, Warde P, Bristow RG (2003) Cell death in irradiated prostate epithelial cells: role of apoptotic and clonogenic cell kill. Prostate Cancer Prostatic Dis 6: 73-85.

128. Rodel F, Frey B, Leitmann W, Capalbo G, Weiss C, et al. (2008) Survivin antisense oligonucleotides effectively radiosensitize colorectal cancer cells in both tissue culture and murine xenograft models. Int J Radiat Oncol Biol Phys 71: $247-255$. 
Citation: Sun L, Cabarcas SM, Farrar WL (2011) Radioresistance and Cancer Stem Cells: Survival of the Fittest. J Carcinogene Mutagene S1:004. doi:10.4172/2157-2518.S1-004

Page 12 of 12

129. Hovinga KE, Shimizu F, Wang R, Panagiotakos G, Van Der Heijden M, et al. (2010) Inhibition of notch signaling in glioblastoma targets cancer stem cells via an endothelial cell intermediate. Stem Cells 28: 1019-1029.

130. Rassi H (2009) Stem cell therapy for hereditary breast cancer. Tsitol Genet 43: 80-88.

131. Vlashi E, Kim K, Lagadec C, Donna LD, McDonald JT, et al. (2009) In vivo imaging, tracking, and targeting of cancer stem cells. J Natl Cancer Inst 101: 350-359.

132. Hambardzumyan D, Becher OJ, Rosenblum MK, Pandolfi PP, ManovaTodorova K, et al. (2008) PI3K pathway regulates survival of cancer stem cells residing in the perivascular niche following radiation in medulloblastoma in vivo. Genes Dev 22: 436-448.

133. Blazek ER, Foutch JL, Maki G (2007) Daoy medulloblastoma cells that express CD133 are radioresistant relative to CD133- cells, and the CD133+ sector is enlarged by hypoxia. Int J Radiat Oncol Biol Phys 67: 1-5.

134. Borovski T, De Sousa EMF, Vermeulen L, Medema JP (2011) Cancer stem cell niche: the place to be. Cancer Res 71: 634-639.

135. Soeda A, Park M, Lee D, Mintz A, Androutsellis-Theotokis A, et al. (2009) Hypoxia promotes expansion of the CD133-positive glioma stem cells through activation of HIF-1 alpha. Oncogene 28: 3949-3959.

136. Heddleston JM, Li Z, Lathia JD, Bao S, Hjelmeland AB, et al. (2010) Hypoxia inducible factors in cancer stem cells. Br J Cancer 102: 789-795.

137. Harrison LB, Chadha M, Hill RJ, Hu K, Shasha D (2002) Impact of tumor hypoxia and anemia on radiation therapy outcomes. Oncologist 7: 492-508.

138. Keith B, Simon MC (2007) Hypoxia-inducible factors, stem cells, and cancer. Cell 129: 465-472.

139. Rich JN (2007) Cancer stem cells in radiation resistance. Cancer Res 67: 8980-8984.

140. McMahon S, Charbonneau M, Grandmont S, Richard DE, Dubois CM (2006) Transforming growth factor beta1 induces hypoxia-inducible factor-1 stabilization through selective inhibition of PHD2 expression. J Biol Chem 281: 24171-24181.

141. Brown JM (2007) Tumor hypoxia in cancer therapy. Methods Enzymol 435: 297-321.
142. Folkman J (1971) Tumor angiogenesis: therapeutic implications. N Engl J Med 285: 1182-1186.

143. Mazeron R, Anderson B, Supiot S, Paris F, Deutsch E (2011) Current state of knowledge regarding the use of antiangiogenic agents with radiation therapy. Cancer Treat Rev

144. Kozin SV, Boucher Y, Hicklin DJ, Bohlen P, Jain RK, et al. (2001) Vascula endothelial growth factor receptor-2-blocking antibody potentiates radiationinduced long-term control of human tumor xenografts. Cancer Res 61: 39-44.

145. Huber PE, Bischof M, Jenne J, Heiland S, Peschke P, et al. (2005) Trimoda cancer treatment: beneficial effects of combined antiangiogenesis, radiation, and chemotherapy. Cancer Res 65: 3643-3655.

146. Winkler F, Kozin SV, Tong RT, Chae SS, Booth MF, et al. (2004) Kinetics of vascular normalization by VEGFR2 blockade governs brain tumor response to radiation: role of oxygenation, angiopoietin-1, and matrix metalloproteinases. Cancer Cell 6: 553-563.

147. Andriole GL, Crawford ED, Grubb RL, Buys SS, Chia D, et al. (2009) Mortality results from a randomized prostate-cancer screening trial. N Engl J Med 360 $1310-1319$

148. Skvortsova I, Skvortsov S, Stasyk T, Raju U, Popper BA, et al. (2008) Intracellular signaling pathways regulating radioresistance of human prostate carcinoma cells. Proteomics 8: 4521-4533.

149. Radisavljevic ZM, Gonzalez-Flecha B (2004) TOR kinase and Ran are downstream from PI3K/Akt in H2O2-induced mitosis. J Cell Biochem 91: 1293-1300.

150. Li H, Ren CP, Tan XJ, Yang XY, Zhang HB, et al. (2006) Identification of genes related to nasopharyngeal carcinoma with the help of pathway-based networks. Acta Biochim Biophys Sin (Shanghai) 38: 900-910.

51. Ly TK, Wang J, Pereira R, Rojas KS, Peng X, et al. (2010) Activation of the Ran GTPase is subject to growth factor regulation and can give rise to cellular transformation. J Biol Chem 285: 5815-5826.

152. Barres V, Ouellet V, Lafontaine J, Tonin PN, Provencher DM, et al. (2010) An essential role for Ran GTPase in epithelial ovarian cancer cell survival. Mol Cancer 9: 272.
This article was originally published in a special issue, Stem Cells-Cancer Research handled by Editor(s). Dr. Claudio Luparello, University of Palermo, Italy 